\title{
Cervical Rib a Very Rare Cause of Secondary Raynaud's Phenomenon
}

\author{
*MR Siddiqui1, MS Mahbub², T Mostafiz 3 \\ 1Dr. Md Mahmudur Rahman Siddiqui, Assistant Professor, Dept. of Medicine, Anwer Khan Modern Medical College \\ ${ }^{2}$ Dr. Md. Shahriar Mahbub, FCPS Medicine Course, Dhaka Medical College, Dhaka \\ ${ }^{3}$ Dr. Tasmia Mostafiz, Intern Medical Officer, BIRDEM, Dhaka
}

\begin{abstract}
*Corresponding Author
ABSTRACT

Secondary Raynaud's phenomenon (or syndrome) due to thoracic outlet obstruction or syndrome (TOS) from cervical rib is very rare. Cervical rib occurs in only $1 \%$ of the general population. It is an uncommon cause for thoracic outlet syndrome (TOS). The clinical manifestations of thoracic outlet syndrome are mainly neurological. Arterial complications are rare and potentially severe. The authors report a case of a 30 year-old woman with left cervical rib that developed embolism in the subclavian artery, due to compression.
\end{abstract}

Key Words: Raynaud's phenomenon, Thoracic outlet syndrome, cervical rib, arterial complications

\section{Introduction}

Raynaud's phenomenon was first described by Maurice Raynaud in $1862 .^{1}$ Raynaud's phenomenon consists of spasm of the digital arteries by cold and relieved by heat. If there is no underlying cause, it is known as Raynaud's disease. ${ }^{1,2}$ This affects $5 \%$ of the young women in temperate climates and may be familial. ${ }^{1}$ The disorder is usually bilateral with fingers affected more commonly than toes. It does not progress to ulceration or infarction, and significant pain is unusual. Cold (and emotional) stimuli may trigger vasospasm, leading to the characteristic sequence of digital pallor due to vasospasm, cyanosis due to deoxygenated blood, and rubor due to reactive hyperaemia. ${ }^{1,2,3}$ Secondary Raynaud's phenomenon (or syndrome) occur in older people in association with connective tissue disease (most commonly systemic sclerosis), vibrationinduced injury (from the use of power tools) and thoracic outlet obstruction or syndrome (TOS) (e.g. cervical rib). It is often associated with fixed obstruction of the digital arteries causes' pain, fingertip ulceration, and necrosis. $1,2,3$ Cervical rib occurs in only $1 \%$ of the general population. ${ }^{4}$ It is an uncommon cause for thoracic outlet syndrome (TOS). Less than $10 \%$ are symptomatic. ${ }^{5}$ The clinical manifestations of thoracic outlet syndrome are mainly neurological. Although arterial complications are rare, they are potentially severe. ${ }^{6}$ In this case report, a 30 year old lady presented with secondary Raynaud's phenomenon in left hand and on evaluation it had been found thoracic outlet syndrome (TOS) due to left cervical rib.

\section{Case Report}

A 30 years female presented with severe pain of left hand and blackish discolouration of fingertips for last six months and ulceration in the tip of the left fingers for last 15 days. She had no history of fever, polyarthritis, skin rash, oral ulcer, fetal loss, palpitation, dyspnoea, angina or taking any drugs. She had past history of intermittent pain, claudication and Raynaud's phenomenon of same hand for last 1 year. Her blood pressure was $120 / 70 \mathrm{~mm} \mathrm{Hg}$ in both hands. No Pulse was felt in left hand. All pulses in other extremities were felt normally. Pulse rate was $84 / \mathrm{min}$, regular in right hand. Temperature of left hand was lower than right. A firm structure was noted in left supraclavicular region. Left subclavian artery bruit was heard. Other systemic examinations were normal. Investigations revealed $\mathrm{Hb} 12$ $\mathrm{gm} / \mathrm{dl}$, ESR $20 \mathrm{~mm} / \mathrm{hr}, \mathrm{CRP}<6 \mathrm{mg} / \mathrm{L}$, fasting blood sugar $5.1 \mathrm{mmol} / \mathrm{l}$, Rheumatoid factor \& ANA were negative. No coagulopathy was detected and lipid profiles were normal. X-ray revealed left cervical rib. Colour flow Doppler showed thrombus in left subclavian artery. Flow-void was noted in axillary and radial arteries. Cervical rib was the cause of subclavian artery thrombosis in this case of secondary Raynaud's phenomenon due to thoracic outlet syndrome (TOS). Cervical rib was excised. Thromboembolectomy and reconstruction of subclavian artery were done. Patient improved symptomatically and blood flow was restored in left upper limb. 


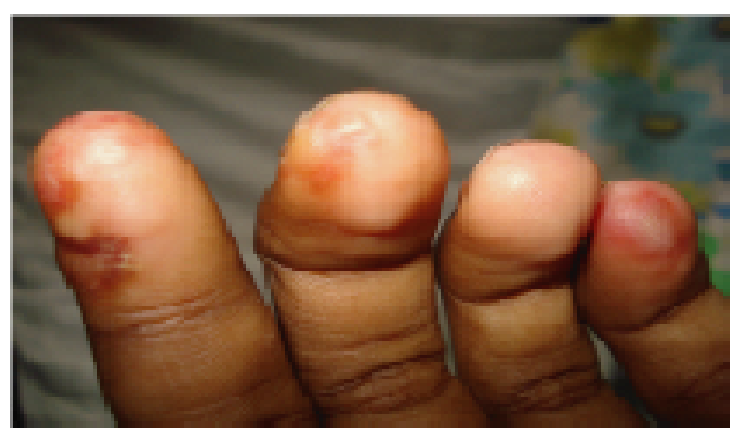

Fig 1: Infarct in the pulp of the fingers

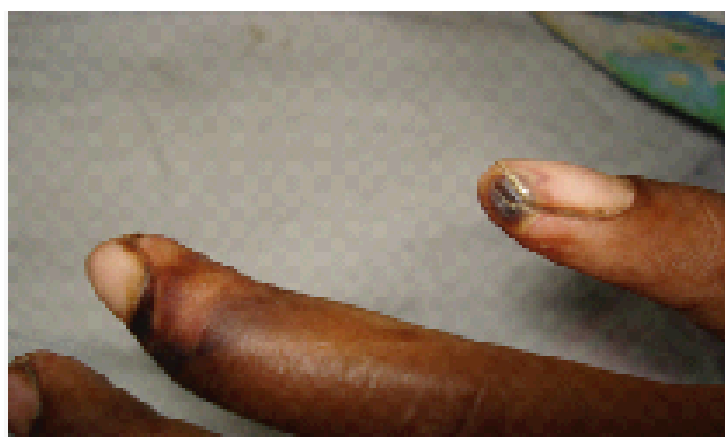

Fig 2: Infarct in the tip of the finger

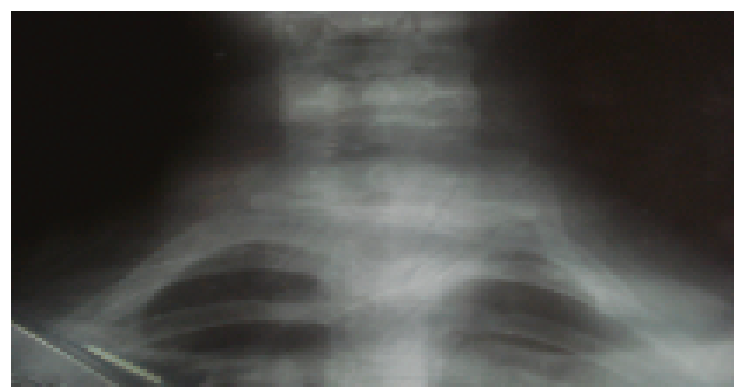

Fig 3: X-ray cervical spine showing cervical rib in the left (arrow).

\section{Discussion}

Thoracic outlet syndrome (TOS) is a general term for compression of the neurovascular structures in the area of the 1 st rib and the clavicle. The cause can be fibrous bands, cervical ribs, anomalous muscles or posttraumatic changes as well as tumors. Symptoms depend on the compressed structure; in most cases (up to $90 \%$ of TOS patients) neurological symptoms are common. Arterial compression by cervical rib like in our case, embolism of the arm and finger arteries can occur. ${ }^{7}$ The cervical rib is a supernumerary rib arising from the costal element of the seventh cervical vertebra. ${ }^{5,6,7}$ It is an uncommon anomaly which is usually detected as an incidental finding on radiographic films. The incidence of cervical rib being $0.6-0.7 \%(1 \%) .^{8}$ Symptomatic cervical ribs are due to the compression of the subclavian artery causing ischemia of the arm and on the brachial plexus causing neurogenic symptoms.5,6 The main complaint is pain. For mild or moderate symptoms a conservative approach with physiotherapy can be helpful. But in case of vascular symptoms and signs of ischemia then surgery is the treatment of choice. For severe cases surgical resection of the compressing structure and the cervical rib is necessary. $6,7,8$

\section{Conclusion}

Thoracic outlet syndrome (TOS) is a very rare cause of secondary Raynaud's phenomenon. Patients with arterial compression in TOS may be at risk of limb-threatening ischemia. Therefore, surgical decompression with arterial reconstruction should be performed as soon as possible. Excellent outcome can be expected with timely diagnosis and treatment.

Acknowledgement: We are grateful to our patient to give consent for this case report.

Conflict of Interest: We have no conflict of interest.

\section{Reference}

1. L. Y. Chan. A Lady with Refractory Raynaud's Disease. Hong Kong Dermatology \& Venereology Bulletin 2000; 8(1): 16-19.

2. Newby DE, Grubb NR, Bradbury A. Cardiovascular disease. In Nicholas AB (ed). Davidson's Principal and Practice of Medicine, 22th edition. UK Churchill Livingstone Elsevier, 2014; 601.3. Clarke CRA. Cardiovascular disease. In Kumar P (ed). Kumar \& Clark's Clinical Medicine, 7th edition. UK Elsevier Limited, 2009;809.

4. Brewin J, Hill M, Ellis H. Prevalence of cervical ribs in a London population. Clin Anat. 2009 April; 22(3): 331-336.

5. Hooper TL, Denton J, McGalliard MK, et al. Thoracic outlet syndrome: a controversial clinical condition. Part 1: anatomy, and clinical examination/diagnosis. J Man ManipTher. June 2010; 18(2):74-83.

6. Ravikumar B.L, Jose V. Francisco Menezes. "Cervical RIB - Upper Limb Ischemia". Journal of Evolution of Medical and Dental Sciences 2014; 3(7):1732-38.

7. Cooke RA. Thoracic outlet syndrome-aspects of diagnosis in the differential diagnosis of hand-arm vibration syndrome. Occupational Medicine 2003; 53: 331-336.

8. Antima Gupta, D.P Gupta, D.K. Saxena, R.P. Gupta. Cervical Rib: It's Prevalence in Indian Population around Luck now (UP). Journal of Anatomical Society of India, December 2012; 61(2): 189-191. 